\title{
Urban Gardeners' Motivations in a Metropolitan City: The Case of Milan
}

\author{
Giordano Ruggeri *, Chiara Mazzocchi and Stefano Corsi \\ Department of Agricultural and Environmental Science, University of Milan, via Celoria 2, 20133 Milan, Italy; \\ chiara.mazzocchi1@unimi.it (C.M.); stefano.corsi@unimi.it (S.C.) \\ * Correspondence: giordano.ruggeri@unimi.it
}

Academic Editor: Han Wiskerke

Received: 8 September 2016; Accepted: 22 October 2016; Published: 27 October 2016

\begin{abstract}
Urban gardening (UG) as a component of urban agriculture (UA) has reached popularity during the last decades. This growing interest depends on several factors including the different functions that have been attributed to UG over the years, operating from the economic to the social, health and cultural levels. While multifunctionality of UG is well documented, only a few studies investigated individual gardeners' motivations, which can be subjective and heavily affected by the local context in which it takes place. The paper aims to detect some peculiar features of Milan city gardeners, in order to highlight the motivations of their activity through an innovative and replicable approach based on multiple correspondence analysis (MCA) and hierarchical clustering analysis (HCA). The analysis has been applied to the Milan case study, in the North of Italy; the results suggest a great importance of the social component of UG, and trace some different gardeners' profiles.
\end{abstract}

Keywords: urban agriculture; urban gardening; food planning; multiple correspondence analysis; survey

\section{Introduction}

Over the last two decades, the attention paid to urban agriculture (UA) and urban gardening (UG) has increased significantly: the main international development agencies, such as Food Agriculture Organization [1], United Nation Development Programme [2], United Nation Human Settlements Programme [3], International Development Research Centre [4], International Water Management Institute [5], Consultative Group for International Agricultural Research [6], Netherlands Urban Agriculture Programme [7] have integrated UA into their policies and programs; urban planners and urban planning associations such as the American Planning Association [8,9] have recognized the usefulness of integrating food systems into land use planning; urban farmers have organized into cooperatives and associations to protect their interests, spread their knowledge, extend their farming projects and inspire other similar initiatives [2,10]; environmental movements have given a boost towards a heated debate about environmental policies and its consequences. In very general terms, urban agriculture can be described as the growing, processing, distribution of food and nonfood plant and tree crops, and the raising of livestock, directly for the urban market or private needs, both within and on the fringe of an urban area [11]. Horticultural activities are by far the most widespread form of agriculture in cities $[2,12]$ to the extent that the terms "urban agriculture" and "urban gardening" are often used as a synonyms even in scientific literature. The scientific debate is rendered even more difficult due to the lack of the clear definitions of UG, due to its heterogeneity in purposes, shapes and management [13]. UG in this research is defined as every no-profit process of intensive growing plants - of every type and variety, in soil or in containers - in an en plein air urban environment. Thus, peri-urban agriculture and every other activity that does not involve the direct cultivation of a 
garden-plot with food crops, such as livestock husbandry, zero-acreage farming [14] or entrepreneurial urban farming, are not covered by this research.

The recent growing interest in UG has to be evaluated in light of a combination of different elements and influences-influences that came from changes in lifestyle, social and ecologist movements, critique to globalization, consciousness about the role of UA in holding back climate change, interest about topics such as food security and others [15]. Moreover, although the number of urban gardeners on a global scale is largely unknown, the number of people involved in UG activities, or who wish they were, has been growing steadily in the past decades. In most cities of developing countries, the proportion of the population involved in UA is very large, reaching as much as $80 \%$ of the population in some Asian cities and more than $40 \%$ of the population in many African countries [16]. In these countries, UA covers a substantial part of the urban demand for fresh green vegetables, fresh milk, poultry and eggs [17]. In the USA, where UG has been studied for a long time [18], an estimated number of 36 million households participated to food gardening activities in 2008, increasing to 43 million for the following year [19]. Of 36 million of participants, 33 million were estimated to be homestead gardeners [19]. Many European cities have a long tradition of gardening, and nowadays waiting lists to access an urban garden are very long [20]. UG practices range from individual initiatives, such as home gardens and illegal gardens in vacant lots [21], to different kinds of gardening initiatives in which organized groups of people are involved in cultivation with a clear set of goals. UG projects come in many different forms such as community gardens, gardening in individual allotments, school gardens, therapy gardens and other structured small-scale food production initiatives [21,22], and they may be established both from gardeners themselves or from external figures such as institutions, non-profit advocacy organizations, medical centers or other private or public organizations [22].

The paper tries to identify some distinctive features of Milan city gardeners, in order to highlight the motivations behind their participation in UG, for helping city planning policies to better address UG projects and promote sustainable practices $[18,23]$. In particular, efforts to open up new cultivable areas in urban environments, as well as the drafting of management and regulations of the various gardening projects, could benefit from the well-rounded knowledge of the participants and their motivations and interests. A greater understanding of the reasons that encourage gardeners to cultivate may be helpful to achieve better management that meets the interests of gardeners and maximizes their participation in the realization of the benefits achievable through UG. At the same time, gardens should provide the opportunity to express and satisfy the various motivations gardeners are interested in, while remaining flexible and receptive to possible changes which may occur both at the individual level as well as in groups [24]. Since motivations that drive people to engage in gardening vary from city to city, the paper provides a replicable methodology, hereby applied to the city of Milan, which can help both to know what motivates gardeners to undertake UG activities and identify profiles in relation to their motivations. In fact, it is not possible to find a single reason why people participate in UG, as multiple motivations coexist. Indeed, while it is interesting to know which are the most important reasons for gardening, it is also interesting to observe to what extent the different motivations coexist and compete to form the impulse to participate in UG. Most of the research on UG motivations is based on qualitative methods, and in some cases is focused more on garden coordinators rather than on gardeners. The methodology allows us to understand the relationship between the different motivations and derive a classification of users that reflects what they expect to achieve from the garden. The application of this methodology for the analysis of case studies in not-developed countries should consider the different contexts in which gardeners live and operate. Indeed, these differences often translate into different ranges of reasons for gardening, which should be taken into account each time. For example, the sale of the produce grown in the gardens could play a crucial role for gardeners in some cities. The methodological approach is quite innovative because it proposes a multivariate analysis using a Multiple Correspondence Analysis (MCA) performed on data retrieved from questionnaires collected from a Milan gardeners' sample, then followed by a Hierarchical Cluster Analysis (HCA). 
This research is presented and discussed in six sections: an overview of the current knowledge regarding urban gardeners' profiles is given in the next section, and then functions of UG are presented to assess how gardeners' interests are met through its activities. The fourth section deals with methodology: it presents the design of the survey and the development of the questionnaire, and the context of the case study and data collection and statistical methods. The fifth one summarizes the most significant results and notes of our findings. The last paragraph attempts to draw conclusions and some general sketches.

\section{Profiling Urban Gardening Motivations}

A review of the existing literature on UG revealed few studies that explicitly investigate the motivations behind gardening within an urban context, which have highlighted various aspects of urban gardeners [23,25-28]. A first consideration regards the distinction between urban farming, which is mainly undertaken for profit, and UG, which engagement in depends on a broad spectrum of less materialistic reasons. The definition of gardening provided by Kiesling et al. [29] as "the intersection of nature and culture, personal values and expectations" clearly explains how involvement in UG depends on a complex mosaic of interests, possibilities, expectations, cultures, values and traditions of each individual.

The analysis of the literature reveals that gardening participation is mostly based on desires to access fresh foods, to enjoy nature, and gain health benefits [25]; to produce quality self-grown food; for the experiences of pleasure, passion, and happiness; and for the contact with nature, soil and plants [18]. Similarly, Clayton's survey on backyard gardeners revealed that gardens are appreciated, in order of importance, for the opportunity to enjoy nature, for health-related benefits, for the opportunity to socialize and as a recreational place [23]. Overall, these studies report that the most cited motivations for gardening are attributable to factors related to personal well-being and own pleasure, whether these are achieved through the physical activities that they carry out in the garden, either through contact with nature and vegetables production. The social function of UG is considered more important by gardeners that operate in garden projects that have been created or organized collectively, open to all citizens, precisely for the purpose of developing local social links through social, cultural, or educational activities [28]. On the other side, family gardens are associated with a stronger emphasis on the dimension of food production [18].

Kiesling and Manning [29], in the U.S., found a strong relationship between participation in gardening activities and environmental identity, which reveals a deep and intimate relationship with the environment and nature [29]. Furthermore, Scheromm underlines gardeners' commitment to environmentally friendly practices, even when not necessarily mandated, as well as the need for contact with nature and the desire to learn and test their knowledge [18].

Although many motivations behind UG participation are common across gardeners from different contexts, the range of motivations for UG is very broad, and different degrees of importance are given to each. Birky and Strom [30] posited that such diversity of motivations represents a key feature of UG, which will lead to urban gardens remaining a lasting feature of city neighborhood landscapes. A second consideration deals with the difference in terms of localization of UG projects in developing countries rather than in the developed ones, in relation to the aims. In developing countries, motivations related to savings and physical access to fresh, nutritious and healthy food are usually given greater emphasis than in developed countries [31,32]. UA is a feature with a long history in the cities of developing countries [31]. In many cases, UG is helping poor people to cope with food scarcity and hunger, also providing them access to an additional viable income. In recognition of these functions of gardening, many international organizations are promoting the development of UG initiatives within their projects, contributing to the spread of gardening initiatives in developing countries [33].

However, even in the wealthiest of global northern cities, there are pockets of severely food insecure communities using UG as a coping strategy and to contrast the perilous impacts of 
unhealthy food outlets clusters (e.g., fast-food chains and takeaways) which tend to prevail in those neighborhoods.

Our research focuses on UG in reality, well-placed in the context of the global north, the city of Milan. Furthermore, reasons for UG vary according to other external influences, such as geo-political and socio-economical contexts. Alber and Kohler [34] argue that in some Eastern European countries, such as Bulgaria and Romania, UG represents a coping strategy for the poorest sections of the population to react to economic difficulties. In the global north, which we refer to, economic motivation seems to be less relevant for urban gardeners, and even if the amount of produce represents a key factor for gardeners, growing their own food does not necessarily mean they do it to save money [28,30]. Glavan et al. [35] compared UG in three European cities, Ljubljana, Milan and London, and they show that although some common elements, such as the desire to have more healthy food or relaxation, are common motivations to all gardeners, some differences exists. In particular, motivations related with saving money are more a concern for gardeners in Ljubljana rather than in Milan. This difference in expectations also affects the shapes and yields of gardens in different cities: findings from case studies of a number of cities across Europe reveal that the typology of garden reflects the different motivations of the gardeners involved, while at the same time it may frame the motivations of new gardeners [24]. In the same way, the yearly gross margin per $100 \mathrm{~m}^{2} /$ garden for the three cities, calculated as the total revenue multiplied by the total cost, shows that Ljubljana has a gross margin seven times higher than that of Milan.

\section{Functions of Urban Gardening}

There is a close relationship between the motivations that drive people to undertake UG and the benefits that they expect to get from it [24,36,37]. Drivers of the spread of UG are numerous also because it has been proved to serve several functions: gardening, being inherently multifunctional [38], providing different benefits related to the different functions it holds, operating on economic, social, health and cultural levels.

Concerning health benefits, UG could improve access to salubrious food, both at the individual and community level [39], and it could increase healthy eating [40] and physical activity [41], mental well-being [42], stress relief [25] and improve food knowledge and skills [43].

The economic function of gardening comes in the way it subsidizes grocery expenses, which may not be irrelevant for the poorest people, and it provides people with fresh vegetables that they may not have otherwise been able to access $[44,45]$. Not only could gardening improve physical access to healthy foods, according to some authors it might also serve this function without any additional cost, since vegetables grown in gardens may cost less than vegetables bought in shops [46]. On the other hand, yield from urban gardens is often poor and some thinking is needed regarding how gardens could contribute to making the urban population food-secure [12]. Establishing new organized gardening projects in parks may be also a wise way for local administrations to reduce the costs of park maintenance, as well as to increase the park user base [45]. Furthermore, according to Been and Voicu [47], the opening of a community garden has a statistically significant positive impact on residential properties.

Moreover, in the last years, numerous entrepreneurial activities strictly linked to UG were opened [48], as the rooftop farms connected to restaurants (the Pullman Hotel in Paris), or to UG projects in restored micro-urban spaces in Paris [49], New York [50] or Montreal [51].

Social benefits derived from UG include more interactions, reinforcement of the sense of community within neighborhoods, improved social networks and reduced crime and the possibility for the garden to become a meeting area [25,52-54]. In addition, gardening in the global north has been widely used to address racial, gender, and environmental inequalities with specific projects for the inclusion of one or more specific groups and/or to improve the urban environment and promote sustainable practices [55-57]. 
Urban gardens benefit the environment in many ways: through the increase of pervious surfaces, which reduces storm water runoff, through soil improvement and green usage of organic solid waste by using composting methods, and by strengthening awareness of food and non-food ecology [15,38]. Gardens also provide essential ecosystem services in urban environments such as pollination, seed dispersal, native plant reproduction and preservation of habitat and green corridors for a variety of animal wild species [58,59]. However, Pourias [28] identifies the food function-defined as the "quantitative and qualitative food supply gardens are likely to provide to gardeners" - as the most valued by gardeners and the central function of gardening, the one that contributes to and supports most of the other garden functions.

For the sake of completeness, several authors pointed out some potential risks and limitations of UG [12,60-63]: vegetables grown in urban gardens may indeed be unhealthy due to anthropogenic pollutants and contaminants. For example, proximity to traffic has been proven to lead to increased trace metal content in the biomass of garden produce [62], and soil and water contamination could represent a health risk for urban gardeners [64]. These constraints pose a challenge for policy-makers, such as local institutions and municipalities, for the further development of UG [12,63]. Furthermore, some production systems employed in agriculture are completely unsuitable for an urban environment, which does not offer large areas of cultivable land and does not allow the heavy use of petrochemicals, or the creation of any externalities to the surrounding residents $[38,65]$.

\section{Methodology}

\subsection{Survey Design and Development of the Questionnaire}

The development of a pilot questionnaire resulted from the literature on gardener surveys and from any source of information, formal or informal, regarding gardening in the city of Milan. The pilot questionnaire was pre-tested on a small sample of urban gardeners and tuned up before administration. Questionnaires were useful to collect data from scratch and to gather opinions on UA from a broader base of the general public. Questionnaires are widely used in different disciplines, since they are very cost-effective, not intrusive or stifling for respondents, easy to compile and analyze; they are not influenced by researchers' own opinion and they do not provide any verbal or visual clues that could influence the respondent [66]. On the other hand, this methodology also presents some limitations: first of all, respondents may be likely to answer not as they think, but as they think is expected from them. Furthermore, it cannot obtain spontaneous answers when required, and it does not provide any way of checking misinterpretations and unintelligible replies [66]. Moreover, especially in the case of respondents not accustomed to questionnaires, many efforts to ensure that applications are fully understood and to guarantee the absence of influences among respondents are needed. All these issues were addressed in the drafting stages and pre-testing of the questionnaire, as well as during the explanation of the questionnaire to participants before compilation.

The questionnaire is structured in seven sections, each one for a different topic: growing space, growing techniques, growing skills and knowledge, motivations for gardening, contribution of gardening to food supply and household budget, food growing externalities and general household information. Gardeners were analyzed through this framework in order to obtain an overall view about motives, functions, practices, problems and techniques from the perspective of the gardeners themselves. In the sampling process, we have used a stratified sampling. The population of gardeners in Milan was divided in homogeneous subgroups, representing the different types of UG initiatives that can be found in the city of Milan. Then a random sampling has been performed and gardeners have been contacted [67]. Potential candidates for questionnaire distribution were found mainly thanks to the collaboration of UA project organizers, who were contacted via email to explain the purposes of the research and to schedule some meetings with gardeners. Initiatives which could not be found online, such as e-mail, phone numbers or representatives, were not included in the sample. 


\subsection{Case Study}

The city of Milan has a long tradition of agriculture and gardening. More than half of its surface is intended for agriculture or forestry uses, and there are different types of gardening projects: besides homestead gardens and community gardens, there are also district gardens for social promotion, educational gardens in schools for both parents and pupils, therapeutic gardens in hospitals, flower beds and abandoned spaces transformed by groups of occasional gardeners, small gardens for self-production in social spaces, and horticultural areas integrated in numerous urban parks [68,69].

Over the last years, the city of Milan has been increasingly recognizing the importance of UA, designing new policies and reformulating and amending existing ones. On 21 September 2012 the City Council of Milan approved the guidelines for entering into agreements with non-profit organizations in order to create new urban gardens in the municipality, at no cost for gardeners and reduced execution time [70]. With this resolution the municipality committed to facilitate the establishment of new gardens in order to enhance and recover abandoned green areas, spreading the hobby of agriculture, fostering social formations, promoting accessibility of green areas and spreading participatory management of the territory. As a result of this political decision, the projects dedicated to UA have increased. Allotment gardens in Milan consist mainly of plots situated on public and municipal-owned land, exclusively intended for horticultural use and private consumption. The use of the plots is subject to an appropriate municipal regulation and to the payment of a yearly fee, in most cases with the possibility to use water provided by the municipality.

A growing number of new gardens have been established, and many others are planned to be opened in the next years in vacant spaces owned by municipalities, following requests by voluntary associations as well as individual citizens.

In 2015, the city of Milan promoted the Milan Urban Food Policy and Framework for Action Pact, which was signed on 8 October by the mayors of over 100 cities around the world. The Pact aims at creating a network of cities committed to shaping resilient, sustainable local food supply chains and good food cultures, also through the exchange of ideas and suggestions on how to concretely address common problems [71]. It includes the commitment to develop and implement policies that promote fair, sustainable and resilient food systems and a framework for action that focuses on six different areas of intervention: governance, sustainable diets, social and economic justice, food production, food distribution and food waste. Though its spectrum of action is very broad, UA and UG have a key role in the Milan Urban Food Policy with regard to the productive, health, educational, environmental and social aspects. The Pact also mentions the need for an inventory of information concerning UA, as well as for the development of multi-sectorial information systems for policy development that enhance the availability, quality, quantity, coverage and management and exchange of data related to urban food systems. In this context, comprehensive knowledge of the gardeners who grow vegetables in gardens in Milan represents a fundamental step.

\subsection{Data and Methods}

The coordinator(s) or founder(s) of each one of the garden projects in Milan were contacted and individually interviewed in order to understand the trajectory, history and the main traits of the different projects. Gardeners were approached either directly in the gardens, at scheduled meetings or through project mailing lists. Questionnaires were mainly distributed at scheduled meetings, and generally held with small groups of four or five gardeners, which were useful for the purpose of explaining the survey and giving guidance for responding to the questionnaire. After receiving the questionnaire, respondents had time to read it, and then each question was illustrated and explained to all the participants, and doubts were alleviated.

Gardeners individually filled in the questionnaires, and any further that doubt emerged during compilation was clarified. 
The distribution and collection of the questionnaires lasted from September 2014 to February 2015; an estimated number between 200 and 250 questionnaires were distributed, resulting in 60 fully completed questionnaires.

Despite the efforts, the amount of information retrieved from this research is larger for allotment gardens than for any other form of UA activity. This is due to the fact that home gardeners and informal gardeners were harder to approach and, especially for the latter, they did not prove to be cooperative. Given the large number of categorical variables of the questionnaires and their belonging to different dimensions of the phenomenon under investigation, as well as a traditional statistic with the common statistical techniques, two exploratory data analysis methods (EDA) were jointly applied in order to synthesize the information deduced from the whole matrix data and classify urban gardeners depending on their motivations for gardening in urban areas. In particular, given the prevalence of qualitative variables in the questionnaire, a Multiple Correspondence Analysis (MCA) was first performed in order to conduct a Hierarchical Cluster analysis on principal components of the MCA (HCA), which is common practice for surveys to classify individuals into groups that are as homogeneous as possible [72].

The following section reports a description of the procedures and details for MCA and HCA, which have been jointly used to characterize some profiles of urban gardeners.

MCA identifies the factors underlying the structure of the data, making it possible to construct principal components optimally summarizing the data, hence highlighting the relations of interdependence between the variables in a small number of them [72,73]. It allows the representation and modeling of complex datasets as clouds of points in a multidimensional Euclidean space; results are therefore interpreted on the basis of relative positions of the points and their distribution along the dimensions. MCA studies individuals, variables and categories. As for the study of individuals, two individuals are close to each other if they answered the questions the same way. The focus is more on populations rather than on individuals. Studying variables and categories, two categories are close to each other if they are often taken together. MCA may uncover the relationship between variables and the associations between categories as it provides one or more continuous synthetic variables to summarize categorical ones. In this study, qualitative variables related to reasons for gardening were used as the active ones and the other quantitative variables were added as supplementary information.

MCA has been performed as a pre-process for clustering to transform categorical variables into continuous ones and to characterize groups of individuals by categories with a smaller number of variables while retaining as much information as possible. Anyway, analyzing the distribution of variables along the Euclidean space may reveal some interesting aspects of the dataset.

To implement the MCA, seven categorical variables related to gardening motivations were selected from the dataset so that explained variance could be maximized. Questions regarding motivations asked to attribute a value from 1 to 5 to the various reasons for UG; in the phase of data processing, the values from 1 to 3 were categorized as "not decisive values for participation" while the values 4 and 5 were considered "relevant for participation". Variables corresponding to the level of education were considered only as supplementary in the process, and thus they are not directly taken into account in the analysis. Table 1 shows the variables chosen for the MCA and the corresponding coded names for the modalities.

The Hierarchical Cluster analysis (HCA) function aggregates clusters so that "the growth of within-inertia is minimum" [72], which is the same as minimizing the reduction of the between-inertia. In other words, the hierarchical clustering aims at finding data sets or variables that belong together, and at separating them from the other data, resulting in a number of clusters. HCA is performed on the components of a factorial analysis and the hierarchy is represented by a dendrogram [72]. Hierarchical classification was undertaken using the criteria of Ward aggregation [72,74]. The choice of the number of clusters is a central issue of every clustering method, and the HCA function implements the calculation of the optimum number of clusters as it constructs the hierarchy and suggests an optimal level for division, which generally corresponds to the one expected merely from looking at the 
tree. A hierarchical tree may be considered as a "sequence of nested partitions from the one in which each individual is a cluster to the one in which all the individuals belong in the same cluster" [72]. The vertical axis of the dendrogram represents the distance or dissimilarity between clusters, and the horizontal axis represents the objects and clusters. The dendrogram is fairly simple to interpret, each joining of two clusters is represented on the graph by the splitting of a horizontal line into two horizontal lines. The vertical position of the split gives the distance or dissimilarity between the two clusters.

Table 1. Variables and modalities used for the MCA.

\begin{tabular}{|c|c|c|c|c|}
\hline Question & $\begin{array}{l}\text { Variable } \\
\text { Name }\end{array}$ & $\begin{array}{l}\text { Measure } \\
\text { Unit }\end{array}$ & Modalities & $\begin{array}{c}\text { Active/Illustrative } \\
\text { Variable }\end{array}$ \\
\hline \multirow{2}{*}{ I grow food to save money } & \multirow{2}{*}{ Savings } & \multirow{2}{*}{ From 1 to 5} & NO Savings & \multirow{2}{*}{ Active } \\
\hline & & & YES Savings & \\
\hline \multirow{2}{*}{$\begin{array}{l}\text { I think my own grown food is healthier } \\
\text { than food I buy from the shops }\end{array}$} & \multirow{2}{*}{$\begin{array}{l}\text { Healthy } \\
\text { Food }\end{array}$} & \multirow{2}{*}{ From 1 to 5} & NO Health & \multirow{2}{*}{ Active } \\
\hline & & & YES Health & \\
\hline \multirow{2}{*}{ Growing my own food is a good exercise } & \multirow{2}{*}{ Exercise } & \multirow{2}{*}{ From 1 to 5} & NO Exercise & \multirow{2}{*}{ Active } \\
\hline & & & YES Exercise & \\
\hline \multirow{2}{*}{ Growing my own food helps me to relax } & \multirow{2}{*}{ Relax } & \multirow{2}{*}{ From 1 to 5} & NO Relax & \multirow{2}{*}{ Active } \\
\hline & & & YES Relax & \\
\hline \multirow{2}{*}{$\begin{array}{l}\text { Growing food helps improve my } \\
\text { local environment }\end{array}$} & \multirow{2}{*}{$\begin{array}{c}\text { Local } \\
\text { Environment }\end{array}$} & \multirow{2}{*}{ From 1 to 5} & NO Local Env & \multirow{2}{*}{ Active } \\
\hline & & & YES Local Env & \\
\hline \multirow{2}{*}{$\begin{array}{l}\text { I grow food to meet/socialize with } \\
\text { other people }\end{array}$} & \multirow{2}{*}{ Sociality } & \multirow{2}{*}{ From 1 to 5} & NO Sociality & \multirow{2}{*}{ Active } \\
\hline & & & YES Sociality & \\
\hline \multirow{2}{*}{ I grow food to learn new skills } & \multirow{2}{*}{ Abilities } & \multirow{2}{*}{ From 1 to 5} & NO Abilities & \multirow{2}{*}{ Active } \\
\hline & & & YES Abilities & \\
\hline \multirow{4}{*}{ Level of education } & \multirow{4}{*}{ Education } & \multirow{4}{*}{$\begin{array}{l}\text { Multiple } \\
\text { choice }\end{array}$} & elementary school & \multirow{4}{*}{ Illustrative } \\
\hline & & & middle school & \\
\hline & & & high school & \\
\hline & & & degree & \\
\hline
\end{tabular}

Statistical analysis were performed with the SPAD software, version 6.25 .

\section{Results}

\subsection{Description of the Sample}

In order to provide a characterization of the sample, Table 2 reports some general characteristics of the interview participants.

The sample of 60 respondents is predominantly made up of males ( $88 \%)$, the age range is between 35 and 82 years old, and the average age is 66 years old. The most recurring educational qualification among respondents is a high school diploma; the average level of education is between middle school and a high school diploma. By far the largest proportion of the respondents are retired $(87 \%)$; the average monthly income of the respondents' families-computed on the total number of valid responses, $69 \%$, compared with the total ratio of valid responses of $95 \%$-is between 1500 and $€ 2000$. Answers regarding the monthly food budget reveal that almost half of the respondents spend from $€ 200$ to $€ 400$ per month in food expenses. However, it should be noted that questions revolving around family income and expenses are subject to various distortions related to the reluctance on the part of respondents to talk about private matters. It is likely that these values are an underestimate with respect to the real data [75]. The size of gardens varies greatly, both across and within typologies. Most allotment gardens consist of 50-square-meter plots which are divided into individual plots of the size of $25 \mathrm{~m}^{2}$, each one run by two gardeners per time. Some gardens are collectively grown and 
managed. Growing food in both large and small plots, these gardeners grow spaces that range in size from roughly $12 \mathrm{~m}^{2}$ to $125 \mathrm{~m}^{2}$, with a prevalence of plots of $25 \mathrm{~m}^{2}$. Motivations and benefits of gardening were rated from most to least important as reported in Table 3.

Table 2. Descriptive statistics of the sample.

\begin{tabular}{|c|c|c|c|}
\hline & & $N$ & $\%$ \\
\hline & Total & 60 & 100 \\
\hline \multirow{2}{*}{ Age } & Min & 35 & \multirow{2}{*}{ Mean $=66$ years, S.D. $=8.5$} \\
\hline & Max & 82 & \\
\hline \multirow{2}{*}{ Gender } & Male & 52 & 87 \\
\hline & Female & 8 & 13 \\
\hline \multirow{5}{*}{ Education } & Elementary school & 12 & 22 \\
\hline & Middle school & 23 & 38 \\
\hline & High school & 17 & 28 \\
\hline & Bachelor & 2 & 3 \\
\hline & $\mathrm{PhD}$ & 5 & 8 \\
\hline \multirow{2}{*}{ Occupation } & In activity & 8 & 13 \\
\hline & Retired & 52 & 87 \\
\hline \multirow{8}{*}{$\begin{array}{l}\text { Family Income } \\
\text { (per month) }\end{array}$} & Not answered & 19 & / \\
\hline & $€ 499$ or less & 1 & 2 \\
\hline & $€ 500-€ 999$ & 4 & 10 \\
\hline & $€ 1000-€ 1499$ & 16 & 39 \\
\hline & $€ 1500-€ 1999$ & 10 & 24 \\
\hline & $€ 2000-€ 2499$ & 6 & 15 \\
\hline & $€ 2500-€ 2999$ & 3 & 7 \\
\hline & $€ 3000-€ 4999$ & 1 & 2 \\
\hline \multirow{6}{*}{$\begin{array}{l}\text { Family Budget for food } \\
\text { expenses (per month) }\end{array}$} & $€ 199$ or less & 6 & 12 \\
\hline & $€ 200-€ 399$ & 23 & 47 \\
\hline & $€ 400-€ 599$ & 7 & 16 \\
\hline & $€ 600-€ 799$ & 5 & 10 \\
\hline & $€ 800-€ 999$ & 3 & 6 \\
\hline & $€ 1000$ or more & 4 & 8 \\
\hline
\end{tabular}

Table 3. Motivations for gardening.

\begin{tabular}{lcc}
\hline & Mean & SD \\
\hline I think my own grown food is healthier than food I buy from the shops & 4.42 & 0.89 \\
Gardening is a good exercise & 4.39 & 0.83 \\
Gardening relaxes me & 4.39 & 0.87 \\
Gardening is a good way to socialize with other people & 4.24 & 0.96 \\
I think my own grown food is safer than food I buy from the shops & 4.12 & 1.12 \\
Gardening helps to improve the local environment & 3.90 & 1.07 \\
I grow my food to learn new skills & 3.31 & 1.35 \\
I grow my food to reduce my environmental impact & 3.07 & 1.30 \\
I grow my food to save money & 2.89 & 1.36 \\
I grow food to sell & 1.19 & 0.83 \\
\hline
\end{tabular}

While responses underscore a wide diversity of motivations behind gardening activities, there is a common emphasis on the healthiness of self-grown vegetables as well as on the numerous health, social and environmental benefits related to gardening.

Gardeners think their landscaping practices have slightly more than a moderate impact on the local ecosystem but they do not mention environmental concerns as a motivation for undertaking gardening. Economic arguments are barely considered; saving money was cited by the majority of the respondents as an irrelevant motivation. Social motivations are considered particularly important, 
and many responses emphasize the ways in which gardening fosters community by strengthening relationships with other gardeners, through conversation and exchange of seedlings or crop surpluses. Eventually, classifying the reasons for gardening by the importance of each motivation reveals that individual motivations seem to prevail over social and environmental ones, in particular in the form of gaining healthy, quality and fresh food, physical exercise and mental relaxation. Then come motivations related to socialization, and then those related to local environment improvement and learning of new abilities and skills.

When asked "What inspired you to start growing your own food?", 80\% of the respondents advanced personal motives, such as pleasure, self-fulfillment and curiosity; almost $30 \%$ of the gardeners traced the reason for gardening to family tradition. Other cited reasons are socialization, learning new skills and the onset of retirement.

The average annual expenditures for gardening activities show relatively low values, ranging from $€ 20$ to $€ 200$ with an average $€ 70$. Though only $18 \%$ of respondents expressed satisfaction over the produce of gardens from an economic point of view, the vast majority of interviewed gardeners declared themselves only partially satisfied, in most cases because of the high incidence of theft of the scarce productions of gardens. Gardeners who participated in the interviews did not tend to grow sufficient food to sustain themselves and their families. However, about a third of the respondents did claim to grow a substantial quantity of fresh produce, and some of them stated that they were self-sufficient in at least some foods through the harvest season. For most of the gardeners the garden produce plays a strictly supplementary role, filling gaps in their diets.

As Scheromm [18] discovered surveying gardeners in Montpellier, our results confirm the presence of a disconnection between the environmentally friendly practices of the gardeners and their habits of food purchase. In fact, despite the vast majority of respondents describing their own method of cultivation using terms such as organic and biodynamic, so much that the sum of the two answers collects about $70 \%$ of the responses, only $42 \%$ of them preferentially buy organic products. At the same time, almost the $65 \%$ of the respondents agreed with the sentence "Organic or biodynamic agriculture is the only proper way to produce healthy food".

Most of the gardeners reported to individually manage the cultivation of their own garden, but almost half of the respondents declare that they are sometimes helped by other gardeners. This relationship of collaboration is reinforced by other dynamics that come with gardening, such as the exchange of seeds and seedlings, the exchange of knowledge and the joint management of tools and shared places.

\subsection{Results and Discussion}

Regarding the MCA results, the MCA function keeps the first two dimensions, which together-after the Benzecri correction [76] - explain 99.16\% of the total inertia: the first dimension itself explains $90.38 \%$ of the total inertia, while the second one explains $8.78 \%$. Through the analysis of the distribution of the variables and modalities on the two-dimensional plane, we were able to draw conclusions about the meaning of the axes.

Figure 1 shows the plot of the component loadings, which corresponds to the positions of the original variables in the two-dimensional space identified by the MCA. Projecting each of the vectors on one of the axes of the two-dimensional space allows us to identify the contribution of each variable to the dimension. Table 4 shows the values of the contributions of each modality to the formation of the two axes; higher values signify great weight in the construction of the corresponding axis.

First of all, we can appreciate that modalities projected on the space identified by the MCA axis are distributed mainly along the first axis, which is the one that explains most of the variance of the sample. 


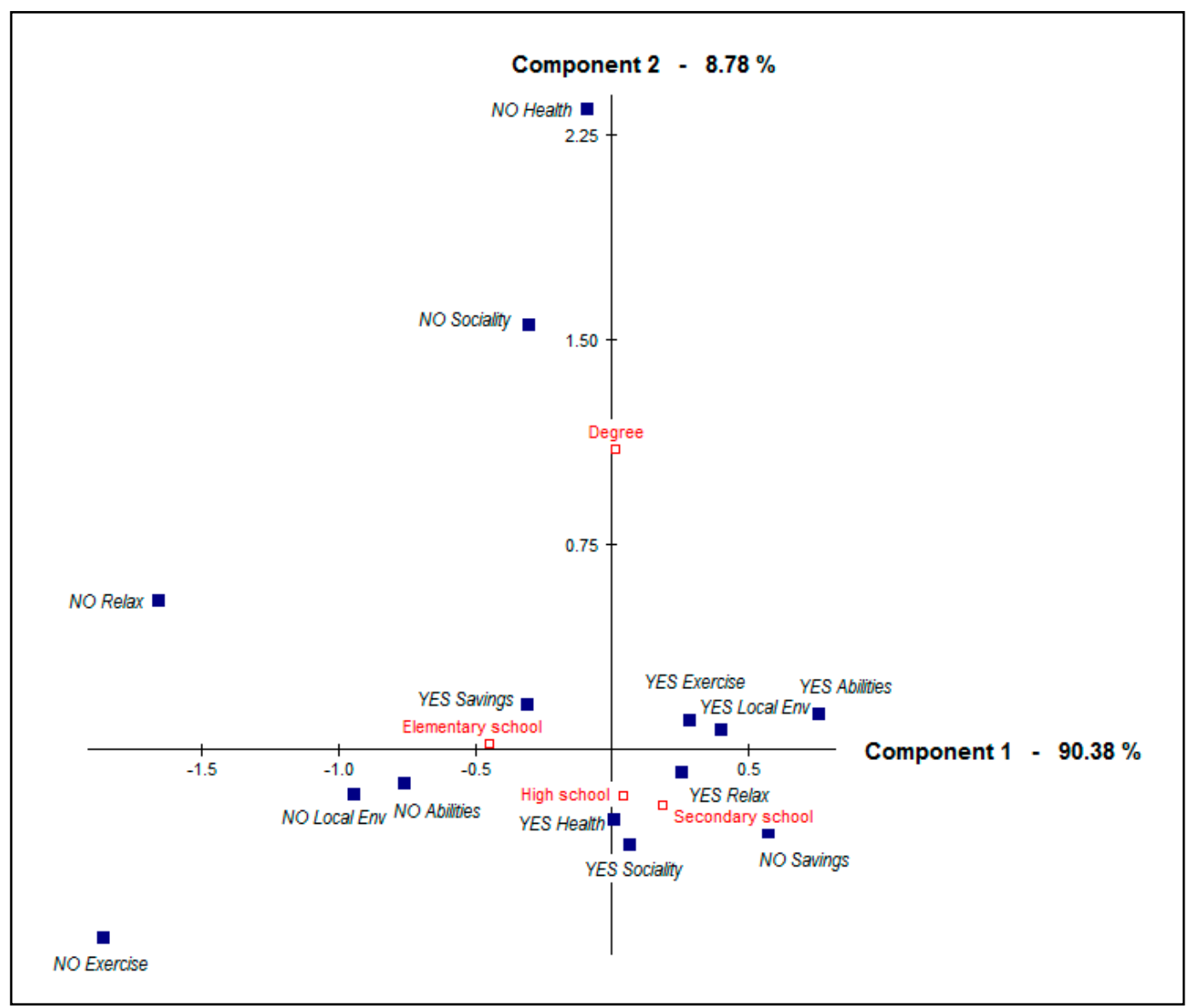

Figure 1. Results taken from MCA; position of the original modalities in the two-dimensional space.

Table 4. Contribution of the variables to the MCA first and second components.

\begin{tabular}{|c|c|c|c|c|}
\hline Variable Name & Modalities & Component 1 (\%) & Component 2 (\%) & Total (\%) \\
\hline \multirow{3}{*}{ Savings } & NO Savings & 5.4 & 2. & \multirow{3}{*}{12.00} \\
\hline & YES Savings & 2.9 & 1.3 & \\
\hline & Total Savings & 8.3 & 3.7 & \\
\hline \multirow{3}{*}{ Healthy food } & NO Health & 0.0 & 4.5 & \multirow{3}{*}{45.1} \\
\hline & YES Health & 0.0 & 40.6 & \\
\hline & Total Healthy food & 0.0 & 45.1 & \\
\hline \multirow{3}{*}{ Exercise } & NO Exercise & 3.4 & 0.7 & \multirow{3}{*}{30.8} \\
\hline & YES Exercise & 21.9 & 4.8 & \\
\hline & Total Exercise & 25.3 & 5.5 & \\
\hline \multirow{3}{*}{ Relax } & NO Relax & 2.7 & 0.4 & \multirow{3}{*}{23.5} \\
\hline & YES Relax & 17.4 & 2.9 & \\
\hline & Total Relax & 20.1 & 3.4 & \\
\hline \multirow{3}{*}{$\begin{array}{c}\text { Local } \\
\text { Environment }\end{array}$} & NO Local Env & 5.4 & 0.3 & \multirow{3}{*}{18.9} \\
\hline & YES Local Env & 12.6 & 0.6 & \\
\hline & Total Local Env & 18.0 & 0.9 & \\
\hline \multirow{3}{*}{ Sociality } & NO Sociality & 0.2 & 7.4 & \multirow{3}{*}{41.3} \\
\hline & YES Sociality & 0.8 & 32.9 & \\
\hline & Total Sociality & 1.0 & 40.3 & \\
\hline \multirow{3}{*}{ Abilities } & NO Abilities & 13.7 & 0.6 & \multirow{3}{*}{28.5} \\
\hline & YES Abilities & 13.7 & 0.6 & \\
\hline & Total Abilities & 27.3 & 1.2 & \\
\hline
\end{tabular}


The first dimension (horizontal) opposes two kinds of sets of motivations with a special focus on psychological well-being: in particular, the positive semi-axis expresses a marked preference for gardening as a means for physical and psychological well-being and learning new skills. At the same time, the modalities expressing a lack of interest in saving money through gardening and positive interest toward the local environmental effects of gardening are located on the same semi-axis. Conversely, on the negative side of the axis are the modalities that show no interest in psychological well-being nor the environmental function of gardening.

The second axis distinguishes two kinds of motivations: on the positive side, increased healthiness of self-grown food and socializing motivations are not regarded as relevant, while on the negative semi-axis these reasons are regarded as important.

With regard to the illustrative variables, only the variable "level of education" is found to be significant and visually appreciable on the plane of the MCA. Its modalities do not seem to be ordered strictly according to one of the two axes, but it can be seen that the highest level of education is associated with the positive side of the second component (low importance for environmental and social motivations), and the lowest level of education is associated with the negative side of the first axis (Yes savings) and the other two modalities that are located on the positive side of the first component. Variables such as age, gender, income and occupation were not significantly represented and were therefore excluded from the analysis.

The first component enlightens two distinct conceptions of gardening: the first one represents gardeners whose commitment stems from the desire to engage in a healthy outdoor activity, with evident effects on local environment and little consideration of economic reasons. The second one represents individuals who engage with gardening more for the yield rather than for other benefits or functions. The distribution of modalities along this axis reveals that only economic motivations are clearly separated from the rest of the reasons for UG, which are located one near the other on the positive side of the first axis.

The second axis distinguishes gardeners according both to motivations related to the healthiness of self-grown food and the inclination to sociality, in particular on the positive side are the modalities "NO Health" and "No Sociality". The distribution of these two modalities on the second component, at a distance from the origin of the axes, reveals that they have been often chosen together by respondents, meaning that gardeners who do not undertake UG for social motivations are also those who generally do not think of their self-grown vegetables as healthier than those purchased in shops or markets.

The components obtained through the MCA were used for the Ward's Hierarchical Clustering analysis, as the procedure requires continuous values rather than categorical ones. Variables included in the clustering analysis were the same as used for the MCA and a three-cluster-based solution was selected, established on statistical criteria and interpretability.

Figure 2 shows the projections of individuals grouped by clusters and the centroids of the different clusters, proportional to the number of individuals of each group, on the two-dimensional space identified by the MCA axes. Figure 3 shows the dendrogram and the point at which it has been cut during the HCA analysis; it also highlights the numerousness of gardeners in the different clusters.

In Table 5, clusters are described according to the most important variables and modalities of each cluster. The value "\% CLU/MOD" represents the ratio between the cluster and modality in percentage, "\% MOD/CLU" represents the ratio between the modality and cluster in percentage, and "Global" is how much each modality is chosen by the whole sample.

The distribution of the individuals in the three clusters reveals that the first one accounts for $53 \%$ of the respondents, the third one for $26 \%$ and the second one only for $21 \%$ of the sample.

The first cluster includes gardeners who undertake gardening by virtue of its multi-functionality and for the different functions that it is able to provide. In particular, gardeners of this cluster reported high values for motivations related to the improvement of the environment, sociability, learning new abilities, relaxation, exercise and healthiness of garden produce. At the same time, members of this 
cluster are characterized by a low value for economic motivations. Based on these attributes, Cluster 1 was named the "Confidents" group.

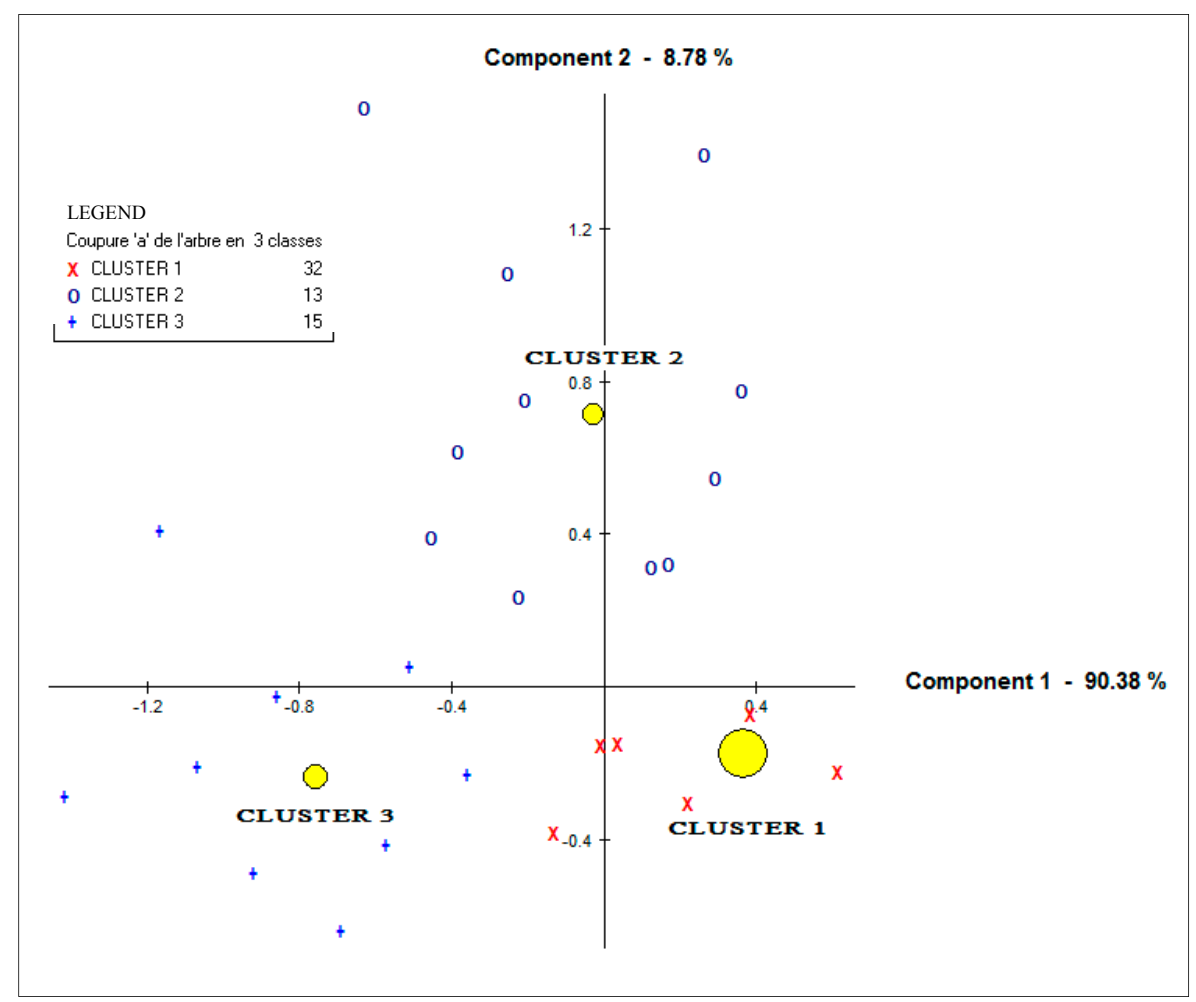

Figure 2. HCA results, individuals divided by clusters and centroids of the clusters screened in the two-dimensional space.

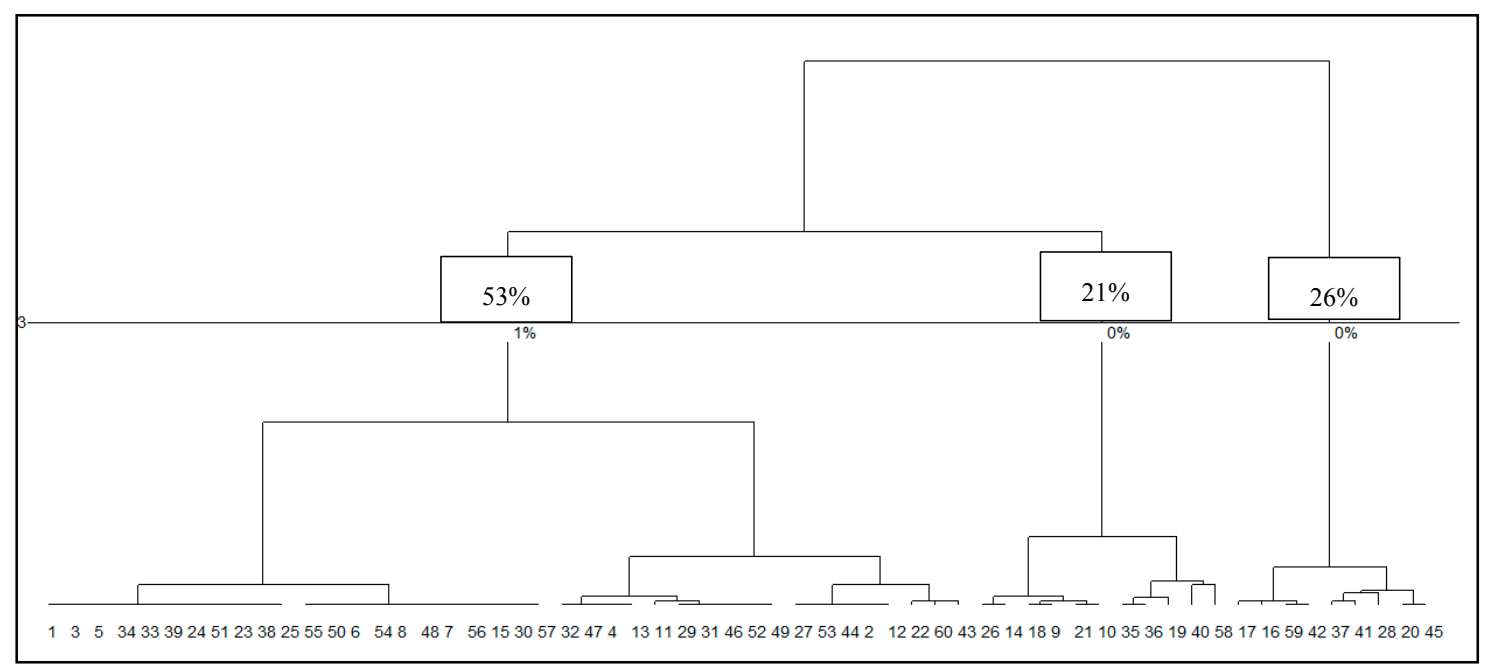

Figure 3. Hierarchical cluster analysis solution, dendrogram.

Following, in order of the number of individuals of each cluster, the third cluster includes gardeners who do not see gardening as a hobby, nor as a tool to learn new skills or improve the local environment. On the contrary, these individuals are driven by an economic motivation and face the garden with more marked production intentions rather than for the other numerous garden functions. Due to the great emphasis on savings and the lack of interest in psychophysical well-being gained through gardening, cluster 3 was named "Savers". 
Table 5. Description of the clusters according to their most important modalities.

\begin{tabular}{cccccc}
\hline Modalities & Variable & V. Test & \% CLU/MOD & \% MOD/CLU & \% Global \\
\hline \multicolumn{5}{c}{ Cluster 1 } \\
\hline Local environment & YES Local Env & 4.14 & 71.43 & 93.75 & 70 \\
Sociality & YES Sociality & 3.84 & 65.31 & 100.00 & 81.67 \\
Abilities & YES Abilities & 3.42 & 76.67 & 71.88 & 50.00 \\
Relax & YES Relax & 3.03 & 61.54 & 100.00 & 86.67 \\
Exercise & YES Exercise & 3.03 & 61.54 & 100.00 & 86.67 \\
Healthy food & YES Health & 2.43 & 59.26 & 100.00 & 90.00 \\
Savings & NO Savings & 2.36 & 76.19 & 50.00 & 35.00 \\
\hline \multicolumn{7}{c}{ Cluster 2 } \\
Sociality & NO Sociality & 5.37 & 90.91 & & \\
Healthy food & NO Health & 3.98 & 100.00 & 46.92 & 8.33 \\
Level of education & Degree & 2.67 & 71.43 & 38.46 & 11.67 \\
\hline \multicolumn{7}{c}{ Cluster 3 } & & \\
\hline Exercise & NO Exercise & 4.56 & 100.00 & 53.33 & 13.3 \\
Abilities & NO Abilities & 4.53 & 50.00 & 100.00 & 50.00 \\
Local environment & NO Local Env. & 3.80 & 61.11 & 73.33 & 30.00 \\
Relax & NO Relax & 2.87 & 75.00 & 40.00 & 13.33 \\
Savings & YES Savings & 2.49 & 35.90 & 93.33 & 65.00 \\
\hline
\end{tabular}

Members of the second cluster are distinguished from the others for their lack of interest in aspects related to the healthiness of self-grown food and sociability through gardening. These individuals are, in fact, mainly distributed on the second component of the MCA, the one that expresses the social and health-related reasons. As for the first component, individuals are distributed evenly around the axis. The reasons why these individuals undertake gardening activities do not make them ascribable either to the first or the third cluster: the main feature that distinguishes them from the other gardeners is that they seem uninterested in socializing. At the same time, they do not believe the food produced in the garden to be healthier than the food they purchase, and they are also generally well educated with the level of education of a university degree. Due to the lack of emphasis on social motivations and the healthiness of self-grown food, cluster 2 was named the "Individualists" group.

The descriptive characteristics of the individuals in the three clusters confirm their characterization by HCA. The "Confidents" is the best cooperating group among the three clusters. Its members are typified by the highest percentage of people that practice seed and seedling exchanges, which is $72 \%$ of the members, compared to $50 \%$ for the total sample, and the highest level of people used to get help to carry out the work in the garden by other gardeners, relatives or friends (56\% compared to $42 \%$ for the total sample).

Concerning the "Individualists", members of this cluster declare to spend the highest amount of money to finance their gardening activities, $€ 151$ per year, compared to gardeners in clusters 1 and 3 who declare a very similar average expense of $€ 63$ and $€ 56$ per year. This could mean that "Individualists" are more interested in experimenting with new cultivations and investing in their activity without paying too much attention to saving money, as is visible from the cluster analysis. At the same time, they are not interested in socializing with other gardeners, since only the $8 \%$ of the individualists do that, and they do not ask other people for any help (8\%).

The "Savers" group declares the highest values of family needs satisfied with self-grown food $(47 \%)$ and, as already said, the minimum investment in expenses ( $€ 56)$.

All these elements could be interesting in order to better comprehend gardeners' features and the differences among them in terms of motivations. As a first consideration, it is possible to highlight how the majority of the respondents fall within the first cluster, the "Confidents". This cluster shows a very positive approach in terms of social and environmental gardening benefits and a low appreciation 
for the economic ones. A second consideration could be made about the "sociality" variable. In fact, the variable "sociality" appears in the modality of "YES sociality" in the first group as one of the main variables influencing the cluster composition, while the modality "NO sociality" appears only in the second cluster, which is composed of only 15 people. This means that this variable has a strong importance only in its positive meaning (YES sociality), whereas sociality is not considered as one of the main motivations for cluster 3, and at the same time it does not appear as the "NO sociality" modality: the "Savers" group merely prefers the economic motivation to the social one but they do not refuse it or reject it as occurs for the "Individualists" cluster. This seems to suggest that the social function of gardening, even in Milan, still represents an important driver for gardeners, as confirmed by the many results highlighted in the literature analysis [18,23].

A third consideration, which is strictly related to the second one, regards the "save money" motivation. In fact, the variable "Savings" appears in its positive modality (YES savings) only for the "Savers", while the "Confidents" show, among their main motivations, the modality "NO savings". If it is true that the "Savers" represents only a small number of gardeners, at the same time it is impossible not to highlight the presence of a part of the sample that considers gardening as a way to save money.

A similar consideration could be made for the rest of the variables included in the clusters "Confidents" and "Savers": all these variables appear in the two clusters in their two opposite modalities, except the "sociality" variable, which appears only in the "YES sociality" modality, and the "healthy food" variable, which is included in its negative modality ("NO Health") only for the "Individualists". So, as the "sociality" variable could be considered as one of the main variables characterizing the choices of the respondents, the same conclusion could be drawn for the "healthy food" variable, as proven by many studies [23,25-27].

\section{Conclusions}

UG is an expanding phenomenon worldwide, and it is complex, various and widespread. This paper presents a methodological approach which is replicable to different contexts for studying gardeners' motivations and trace profiles. Regarding the main contribution of this work in relation to the results of the analysis in the city of Milan, it is possible to draw some interesting conclusions.

The first one is related to the main motivations that emerged from the study: in Milan, most of the respondents express the desire for healthier food and personal wellness as the driving reasons for practicing UG in the city. As evidenced by other studies $[18,23,25]$, the top three motivations for gardening listed in Table 3 are attributable to personal well-being and one's own pleasure, but they can be linked to the broader category of public health as well. Indeed, the desire for more nutritious fresh produce, exercise, relaxation and food safety, which emerge as the dominant drivers for engaging with UG in the city, represents an important objective with regard to public health issues in urban areas.

Secondly, the only descriptive characteristic of the sample which proved to be significant in terms of MCA is the educational level of the respondents, clearly distributed in the three clusters, as shown in the results. This means that the level of education is still a very important feature in the field of UG, which, among other things, could also impact the approach and motivations towards gardening in Milan.

Lastly, some policy guidance could be suggested. Considering the possibility of producing healthier food and the sociality, it is possible to say that a planning policy that cares to dedicate spaces and projects to foster sociality and participation in UG could certainly be well received by the community of Milan gardeners. At the same time, this kind of policy intervention which focuses on sociality could be accompanied by planning actions that take into consideration the existence of gardeners whose main interest in UG is merely the "food function" of UG. This can be said for some of the cluster "Individualists", who are citizens that practice UG for individual motivations, and for the group of "Savers", who, for need or for personal reasons, are interested in saving money. These gardeners should not be ignored, since the benefits that the city draws from their work are the same as for the others, independently from the reasons that drive them: management of urban green 
areas, participation in outdoor activities and creation of social entities that operate in public spaces. Moreover, even in cities in developed countries, there are pockets of poor segments of the population that could benefit from the saving function of UG more than others. In particular, considering the amount of studies in developed countries that show how UG represents a coping strategy to save money [12], on a par with social projects, more initiatives that meet the needs of the poorest population groups should be implemented.

The great emphasis given by Milan gardeners to health-related motivations for gardening should encourage more quality-related interventions, e.g., incentives for soil testing services for gardeners, the development of real-time soil quality map of the city or the study of potential pollutant sources near the gardens. Moreover, pondering the interest of Milan gardeners in exchanging horticultural practice, healthy food, organic production and other UG practices as shown in the survey results, it could be interesting to propose innovative and experimental solutions for new forms of UG, bringing together the different functions of the vegetable gardens as already occurs in other cities around the world. Cities such as Brighton [77], Cleveland [78], Vancouver [79] and Paris [28] have already embedded UA and UG into planning policy, and ordinances have been adopted to increase, enable and facilitate UA in its different forms and functions. Finally, this work is a first exploratory step and it sets the stage for subsequent research on the explored topics which still have a wide margin in research.

Author Contributions: The authors contributed in the same way to the research. Chiara Mazzocchi, Stefano Corsi and Giordano Ruggeri developed the concept and the design of the study. Giordano Ruggeri collected and analyzed the data. Giordano Ruggeri and Chiara Mazzocchi drafted the manuscript. All authors read and approved the final version.

Conflicts of Interest: The authors declare no conflict of interest.

\section{References}

1. FAO (Food and Agriculture Organization). Urban agriculture: An oximoron? In The State of Food and Agriculture; FAO: Rome, Italy, 1996.

2. UNDP (United Nations Development Program). Urban Agriculture: Food, Jobs and Sustainable Cities; Publication Series for Habitat II, Volume One; UNDP: New York, NY, USA, 1996.

3. UNCHS (United Nations Centre for Human Settlements). Cities in a Globalizing World: Global Report on Human Settlements; Earthscan Publications Ltd.: London, UK, 2001; Available online: http://www.un.org/ en/events/pastevents/pdfs/Cities_in_a_globalizing_world_2001.pdf (accessed on 25 October 2016).

4. Egziabher, A.G.; Lee-Smith, D.; Maxwell, D.G.; Memon, P.A.; Mougeot, L.J.A.; Sawio, C.J. Cities Feeding People: An Examination of Urban Agriculture in East Africa; IDRC (International Development Research Centre): Ottawa, ON, Canada, 1994.

5. Drechsel, P.; Kunze, D. Waste Composting for Urban and Peri-Urban Agriculture: Closing the Rural Urban Nutrient Cycle in Sub-Saharian Africa; IWMI: Colombo, Sri Lanka; FAO: Rome, Italy, 2001.

6. Prain, G. Urban Harvest: A CGIAR Global Program on Urban and PeriUrban Agriculture. Extension Bullettin 575. FFTC; CGIAR (Consultative Group for International Agricultural Research): Lima, Perù, 2006.

7. De Zeeuw, H. Introduction. In Annotated Bibliography on Urban Agriculture; ETC Urban Agriculture Programme: Wageningen, The Netherlands, 2003; pp. 7-20.

8. Drescher, A. The integration of Urban Agriculture into urban planning-An analysis of the current status and constraints. In Annotated Bibliography on Urban Agriculture; ETC-RUAF/CTA: Wageningen, The Netherlands, 2001.

9. Hodgson, K.; Campbell, M.C.; Bailkey, K. Urban Agriculture-Growing Healthy, Sustainable Places; American Planning Association: Chicago, IL, USA, 2011.

10. Taylor, J.R.; Lovell, S.T. Urban home food gardens in the Global North: Research traditions. Agric. Hum. Values 2013, 31, 285-305. [CrossRef]

11. Alison, L.; Jamie, T.; Philip, W.H.; Gaston, K.J. Urban domestic gardens: The extent and structure of the resource in five major cities. Landsc. Ecol. 2007, 22, 601-615.

12. Mougeot, L.J.A. Urban Agriculture: Definition, Presence, Potentials and Risks, and Policy Challenges; International Development Research Centre (IDRC): La Habana, Cuba, 2000. 
13. Ernwein, M. Framing urban gardening and agriculture: On space, scale and the public. Geoforum 2014, 56, 77-86. [CrossRef]

14. Specht, K.; Siebert, R.; Hartmann, I.; Freisinger, U.B.; Sawicka, M.; Werner, A.; Thomaier, S.; Henckel, D.; Walk, H.; Dierich, A. Urban agriculture of the future: An overview of sustainability aspects of food production in and on buildings. Agric. Hum. Values 2014, 31, 33-51. [CrossRef]

15. Mougeot, L.J.A. Agropolis: The Social, Political and Environmental Dimensions of Urban Agriculture; Earthscan and the International Development Research Centre (IDRC): London, UK, 2005.

16. Corbould, Claire. Feeding the Cities: Is Urban Agriculture the Future of Food Security? Future Directions International, 2013. Available online: http://www.futuredirections.org.au/publication/feeding-the-citiesis-urban-agriculture-the-future-of-food-security / (accessed on 25 October 2016).

17. Van Veenhuizen, R. Cities farming for the future. In Cities Farming for the Future: Urban Agriculture for Green and Productive Cities; van Veenhuizen, R., Ed.; RUAF Foundation, IIRR, IDRC: Leusden, The Netherlands; Ottawa, ON, Canada, 2006; pp. 1-17.

18. Scheromm, P. Motivations and practices of gardeners in urban collective gardens: The case of Montpellier. Urban For. Urban Green. 2015, 14, 735-742. [CrossRef]

19. Butterfield, B. The Impact of Home and Community Gardening in America. National Gardening Association. 2009. Available online: http://www.nativeseeds.org/pdf/2009-Impact-of-Gardening-in-America-WhitePaper.pdf (accessed on 25 October 2016).

20. European Cooperation in Science and Technology. Urban Allotment Gardens in European Cities Future; COST: Dortmund, Germany, 2013.

21. Smith, V.M.; Greene, R.B.; Silbernagel, J. The social and spatial dynamics of community food production: A landscape approach to policy and program development. Landsc. Ecol. 2013, 28, 1415-1426. [CrossRef]

22. Pudup, M.B. It takes a garden: Cultivating citizen-subjects in organized garden projects. Geoforum 2008, 39, 1228-1240. [CrossRef]

23. Clayton, S. Domesticated nature: Motivations for gardening and perceptions of environmental impact. J. Environ. Psychol. 2007, 27, 215-224. [CrossRef]

24. Calvet-Mir, L.; March, H.; Nordh, H.; Pourias, J.; Čakovská, B. Motivations behind Urban Gardening: “Here I Feel Alive". In Urban Allotment Gardens inEurope; Routledge: Birmingham, UK, 2015.

25. Armstrong, D. A survey of community gardens in upstate New York: Implications for health promotion and community development. Health Place 2000, 6, 319-327. [CrossRef]

26. Draper, C.; Freedman, D. Review and analysis of the benefits, purposes, and motivations associated with Community Gardening in the United States. J. Community Pract. 2010, 18, 458-492. [CrossRef]

27. Duchemin, E.; Wegmuller, F.; Legault, A.M. Agricultureurbaine: Un outil multidimensionnel pour le developpement desquartiers. Rev. Electron. Sci. Environ. 2010, 10, 2. Available online: https://vertigo.revues. org/10436?lang=pt (accessed on 25 October 2016). (In French)

28. Pourias, J.; Aubry, C.; Duchemin, E. Is food a motivation for urban gardeners? Multifunctionality and the relative importance of the food function in urban collective gardens of Paris and Montreal. Agric. Hum. Values 2016, 33, 257-273. [CrossRef]

29. Kiesling, F.M.; Manning, C.M. How green is your thumb? Environmental gardening identity and ecological gardening practices. J. Environ. Psychol. 2010, 30, 315-327. [CrossRef]

30. Birky, J.; Strom, E. Urban perennials: How diversification has created a sustainable community garden movement in The United States. Urban Geogr. 2013, 34, 1193-1216. [CrossRef]

31. De Bon, H.; Parrot, L.; Moustier, P. Sustainable urban agriculture in developing countries. A review. Agron. Sustain. Dev. 2010, 30, 21-32. [CrossRef]

32. Mok, H.; Williamson, V.G.; Grove, J.R.; Burry, K.; Barker, S.F.; Hamilton, A.J. Strawberry fields forever? Urban agriculture in developed countries: A review. Agron. Sustain. Dev. 2014, 34, 21-43. [CrossRef]

33. Baudoin, W.; Drescher, A. Urban Agriculture For Sustainable Poverty Alleviation and Food Security. Available online: http://www.fao.org/fileadmin/templates/FCIT/PDF/UPA_-WBpaper-Final_October_ 2008.pdf (accessed on 25 October 2016).

34. Alber, J.; Kohler, U. Informal food production in the Enlarged European Union. Soc. Indic. Res. 2008, 89, 113-127. [CrossRef]

35. Glavan, M.; Pintar, M.; Černič-Istenič, M.; Sali, G.; Corsi, S.; Mazzocchi, C.; Monaco, F.; Schmutz, U.; Bos, E.; Kneafsey, M.; et al. Food Metres. Food Planning and Innovation for Sustainable Metropolitan Regions. 2015. 
Available online: http:/ /www.foodmetres.eu/wp-content/uploads/2015/08/D4.3-Lesson-Learned-onUrban-Gardening-Phenomenon_D_optim.pdf (accessed on 25 October 2016).

36. Corrigan, N. Community Gardening, Motivation and Health Benefits. Bachelor of Science in Human Nutrition and Dietetics BSc; University of Dublin, Trinity College and Dublin Institute of Technology: Dublin, Ireland, 2011.

37. Gelsi, E. Gardening in the street: Sociality, production and consumption in Northey street city farm. In Urban Agriculture Noteg City Farmer, Canada's Office of Urban Agriculture. In Lee SH (2001): Community Gardening Benefits as Perceived among American-Born and Immigrant Gardeners in San Jose, California, USA; Environmental Science Department, University of California: Berkeley, CA, USA, Unpublished paper; 1990.

38. Lovell, S.T. Multifunctional urban agriculture for sustainable land use planning in the United States. Sustainability 2010, 2, 2499-2522. [CrossRef]

39. Brown, K.H.; Jameton, A.L. Public health implications of urban agriculture. J. Public Health Policy 2000, 21, 20-39. [CrossRef] [PubMed]

40. Alaimo, K.; Packnett, E.; Miles, R.A.; Kruger, D.J. Fruit and Vegetable intake among urban community gardeners. J. Nutr. Educ. Behav. 2008, 40, 94-101. [CrossRef] [PubMed]

41. Zick, C.D.; Smith, K.R.; Kowaleski-Jones, L.; Uno, C.; Merrill, B.J. Harvesting more than vegetables: The potential weight control benefits of community gardening. Am. J. Public Health 2013, 103, 1110-1115. [CrossRef] [PubMed]

42. Shaw, S. Gardening and mental health. J. Bot. Gard. Horticult. 2015, 13, 3-13.

43. Barthel, S.; Folke, C.; Colding, J. Social-ecological memory in urban gardens-Retaining the capacity for management of ecosystem services. Glob. Environ. Chang. 2010, 20, 255-265. [CrossRef]

44. Hannah, A.K.; Oh, P. Rethinking urban poverty: A look at community gardens. Bull. Sci. Technol. Soc. 2000, 20, 207-216. [CrossRef]

45. Milburn, L.A.; Vail, B.A. Sowing the seeds of success cultivating a future for community gardens. Landsc. J. 2010, 29, 71-89. [CrossRef]

46. CoDyre, M.; Fraser, E.D.G.; Landman, K. How does your garden grow? An empirical evaluation of the costs and potential of urban gardening. Urban For. Urban Green. 2015, 14, 72-79. [CrossRef]

47. Been, V.; Voicu, I. The Effect of Community Gardens on Neighboring Property Values. Available online: http:/ /lsr.nellco.org/nyu_lewp/46 (accessed on 14 March 2006).

48. Eigenbrod, C.; Gruda, N. Urban vegetable for food security in cities. A review. Agron. Sustain. Dev. 2015, 35, 483-498. [CrossRef]

49. Topager. 2016. Available online: http://topager.com/ (accessed on 25 October 2016).

50. Brooklyn Grange Farms. 2016. Available online: http://www.brooklyngrangefarm.com/ (accessed on 25 October 2016).

51. Concrete Garden Sustainable Urban Agriculture. Available online: http://concretegarden.uvic.ca/ (accessed on 25 October 2016).

52. Hynes, P.H.; Howe, G. Urban horticulture in the contemporary United States: Personal and community benefits. Acta Horticult. 2004, 643, 171-181. [CrossRef]

53. Howe, J.; Viljoen, A.; Bohn, K. New Cities With More Life: Benefits and Obstacles. In Continuous Productive Urban Landscapes: Designing Urban Agriculture for Sustainable Cities; Architectural Press: New York, NY, USA, 2005; pp. 56-60.

54. Church, A.; Mitchell, R.; Ravenscroft, N.; Stapleton, L. 'Growing your own': A multi-level modelling approach to understanding personal food growing trends and motivations in Europe. Ecol. Econ. 2015, 110, 71-80. [CrossRef]

55. Alkon, A.H.; Agyeman, J. Cultivating Food Justice: Race, Class, and Sustainability; The MIT Press: Cambridge, MA, USA, 2011.

56. Reynolds, K.; Cohen, N. Beyond the Kale Urban Agriculture and Social Justice Activism in New York City; University of Georgia Press: Athens, GA, USA, 2016.

57. Taylor, J.R.; Lovell, S.T. Urban home gardens in the Global North: A mixed methods study of ethnic and migrant home gardens in Chicago, IL. Renew. Agric. Food Syst. 2014, 30, 22-32. [CrossRef]

58. Ernstson, H.; Barthel, S.; Andersson, E.; Borgström, S.T. Scale-crossing brokers and network governance of urban ecosystem services: The case of stockholm. Ecol. Soc. 2010, 15, 28. Available online: http: / /www.ecologyandsociety.org/vol15/iss4/art28/ (accessed on 25 October 2016). 
59. Matteson, K.C.; Ascher, J.S.; Langellotto, G.A. Bee richness and abundance in New York City urban gardens. Ann. Entomol. Soc. Am. 2008, 101, 140-150. [CrossRef]

60. Nugent, R. The Impact of Urban Agriculture on the Household and Local Economies. In Growing Cities Growing Food: Urban Agriculture on the Policy Agenda; DSE: Berlin, Germany, 2000.

61. Muñoz, I.; Tomàs, N.; Mas, J.; García-Reyes, J.F.; Molina-Díaz, A.; Fernández-Alba, A.R. Potential chemical and microbiological risks on human health from urban wastewater reuse in agriculture. Case study of wastewater effluents in Spain. J. Environ. Sci. Health 2010, 45, 300-309. [CrossRef] [PubMed]

62. Antisari, L.V.; Orsini, F.; Marchetti, L.; Vianello, G.; Gianquinto, G. Heavy metal accumulation in vegetables grown in urban gardens. Agron. Sustain. Dev. 2015, 35, 1139-1147. [CrossRef]

63. Säumel, I.; Kotsyuk, I.; Hölscher, M.; Lenkereit, C.; Weber, F.; Kowarik, I. How healthy is urban horticulture in high traffic areas? Trace metal concentrations in vegetable crops from plantings within inner city neighbourhoods in Berlin, Germany. Environ. Pollut. 2012, 165, 124-132. [CrossRef] [PubMed]

64. Flynn, K. An Overview of Public Health and Urban Agriculture: Water, Soil and Crop Contamination E Emerging Zoonosis; Cities Feeding People Report 30; International Development Research Centre (IDRC): Ottawa, ON, Canada, 1999.

65. Mazzocchi, C.; Sali, G.; Corsi, S. Analisi Della Fragilità del Contesto Agricolo in Area Periurbana: Uno Strumento per il Governo del Territorio. Ital. J. Reg. Sci. 2013. [CrossRef]

66. Ackroyd, S.; Hughes, J.A. Data Collection in Context, 6th ed.; Longman: London, UK, 1981.

67. Clark, G.; Gordon, D.S. Sampling for farm studies in Geography. Geography 1980, 65, 101-106.

68. Tornaghi, C. Critical geography of urban agriculture. Prog. Hum. Geogr. 2014, 38, 551-567. [CrossRef]

69. Corsi, S.; Sali, G.; Monaco, F.; Mazzocchi, C. The cores of metropolitan areas: Evidence from five European contexts. Territorio 2015, 74, 182-188. [CrossRef]

70. Agricity Milano Metropoli Rurale. Available online: http://www.agricity.it/pagina-di-esempio/coltivami/ (accessed on 25 October 2016).

71. Milan Urban Food Policy. Available online: http://www.milanurbanfoodpolicypact.org/ (accessed on 25 October 2016).

72. Husson, F.; Josse, J.; Pages, J. Principal Component Methods-Hierarchical Clustering-Partitional Clustering: Why Would We Need to Choose for Visualizing Data? Technical Report-Agrocampus. 2010. Available online: http:/ / factominer.free.fr/classical-methods/hierarchical-clustering-on-principalcomponents.html (accessed on 25 October 2016).

73. Guinot, C.; Latreille, J.; Malvy, D.; Preziosi, P.; Galan, P.; Hercberg, S.; Tenenhaus, M. Use of multiple correspondence analysis and cluster analysis to study dietary behaviour: Food consumption questionnaire in the SU.VI.MAX. cohort. Eur. J. Epidemiol. 2001, 17, 505-516. [CrossRef] [PubMed]

74. Ward, J.H. Hierarchical grouping to optimize an objective function. J. Am. Stat. Assoc. 1963, 58, $235-244$. [CrossRef]

75. Tourangeau, R.; Yan, T. Sensitive questions in surveys. Psychol. Bull. 2007, 133, 859-883. [CrossRef] [PubMed]

76. Abdi, H.; Valentin, D. Multiple Correspondence Analysis. 2007. Available online: http://www.utdallas.edu/ herve/Abdi-MCA2007-pretty.pdf (accessed on 25 October 2016).

77. Crockett, T. Food for Thougth. Brighton and Hove City Council's Sustainable Food Strategy. Available online: http:/ / www.bioregional.com/917/ (accessed on 25 October 2016).

78. Fair Food Network (FFN). Cleveland Urban Agriculture Project. Available online: http:// www.fairfoodnetwork.org/what-we-do/projects/cleveland-urban-agriculture-project/ (accessed on 25 October 2016).

79. Sustainable Urban Food Production in the City of Vancouver: An Analytical and Strategy Framework for Planners and Decision-Makers. Available online: http://www.cityfarmer.org/barrsUAvanc.html (accessed on 25 October 2016).

(C) 2016 by the authors; licensee MDPI, Basel, Switzerland. This article is an open access article distributed under the terms and conditions of the Creative Commons Attribution (CC-BY) license (http://creativecommons.org/licenses/by/4.0/). 